\title{
An uncommonly serious case of an uncommon sport injury
} A Abedin, H-C Chen

Br J Sports Med 2005;39:e33 (http://www.bjsportmed.com/cgi/content/full/39/8/e33). doi: 10.1136/bjsm.2004.013524

Background: A 55 year old man sustained a severe ocular injury when hit by a cricket ball even though he was wearing a helmet.

Methods: A suprachoroidal haemorrhage was drained and dense intravitreal blood was removed. An inferior buckle was applied with the use of intraocular gas. A macular haemorrhage resolved slowly.

Results: Despite several surgical procedures over 1.5 years, the final visual acuity of the patient was only $6 / 60$ because of a dense macular scar.

Conclusions: Helmets worn as protection when playing cricket need to be designed better and be of better material. Eye protection should be worn at all levels of play.

$\mathrm{S}$ evere ocular injury from sport is uncommon. ${ }^{1}$ Such an injury resulting from impact by a cricket ball is even more uncommon. ${ }^{2}{ }^{3}$ We report the case of a patient with severe choroidal and intravitreal haemorrhage, requiring drainage of suprachoroidal blood followed by pars plana vitrectomy. The patient also had a small, self-sealed globe rupture without extrusion of ocular contents and without an orbital fracture. The last is a rare occurrence in the absence of an orbital margin fracture. ${ }^{3}$

\section{CASE REPORT}

A 55 year old man was referred to eye casualty from accident and emergency (A\&E) with a painful, red right eye following a cricket ball injury sustained a few hours earlier in a county league game. He had a large curvilinear laceration extending down the right temple which had been repaired in A\&E. He had hand movement vision and a moderate right relative afferent pupillary defect (RAPD). The orbital margins were intact and there was extensive lid oedema with ecchymoses as well as chemosis, causing some restriction of ocular movement (fig 1A). The injury had occurred although the subject had been wearing a cricket helmet. The helmet was dented badly on the right side of the face bars at the area of impact (fig 1B). Further examination revealed the cornea to be unaffected but the anterior chamber to be very deep, with an $0.8 \mathrm{~mm}$ hyphaema and a reacting dilated pupil; the deep anterior chamber was suggestive of an ocular perforation although there was no other sign to suggest this. The lens was intact but there was a dense vitreous haemorrhage. The intraocular pressure was normal. The ultrasonogram (USG) was indicative of choroidal detachment. The patient was admitted for bed rest with antibiotic cover and oral Diamox.

A computed tomography scan showed no orbital fracture. Subsequently, the suprachoroidal haemorrhage was drained. At review a week later, the patient had persistent right RAPD and still had only hand movement vision, with a persisting dense intragel haemorrhage. USG showed a small pocket of residual suprachoroidal blood.

The patient was admitted for right pars plana vitrectomy 3 weeks later. Dense intravitreal blood was removed.
Although his retina was attached, he had extensive retinal dialysis and a small self-sealed globe rupture. There was a large macular scar possibly from an organised subretinal haemorrhage. An inferior buckle was applied with use of intraocular gas. His vision improved to $6 / 24$ with pinhole postoperatively, with slow resolution of the macular haemorrhage. However, an increasing posterior subcapsular cataract was responsible for vision worsening to 6/60 leading to cataract extraction with implantation of an intraocular lens. His final visual acuity was $6 / 60$ because of his dense macular scar.

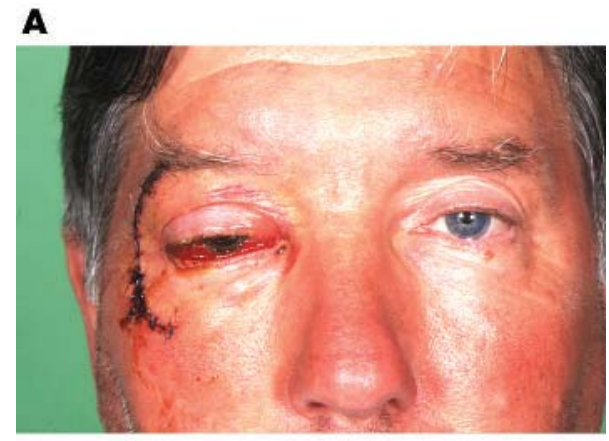

B

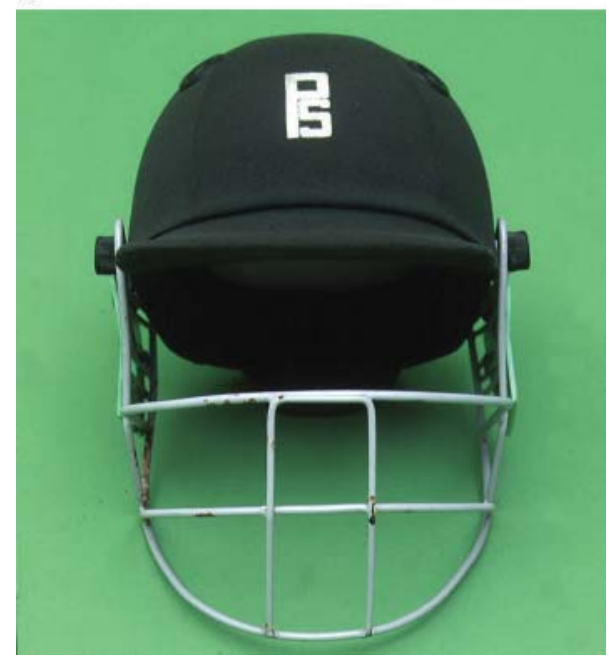

Figure 1 (A) Photograph showing the immediate aftermath of the injury; there is a large repaired laceration on the right temple and severe lid oedema and bruising. (B) The helmet worn by the patient when the injury was sustained, showing a dent on its side at the point of impact of the ball. (Photograph reproduced with consent)

Abbreviations: RAPD, relative afferent pupillary defect; USG, ultrasonogram 
What is already known on this topic

Severe ocular injury resulting from impact by a cricket ball is very uncommon but does occur.

\section{What this study adds}

Severe ocular injury can occur when playing cricket so it is very important that adequate eye protection is worn at all levels of play.

\section{DISCUSSION}

It has been widely advised that adequate protection be worn during sport. ${ }^{2-6}$ Though racket sports are mainly implicated in causing serious eye injury, ${ }^{2}{ }^{3}$ face protection for batsmen is compulsory in cricket. ${ }^{7}$ This seems reasonable in view of the fact that serious injury during cricket play, though uncommon, can cause severe visual loss. ${ }^{8}$ However, as illustrated by our patient, standard helmets may not afford sufficient protection. This is borne out by studies on different types of helmets. ${ }^{9}$

Our patient underwent several surgical procedures over a prolonged period of 1.5 years with a final visual acuity of only 6/60. This was the direct result of a cricket ball injury while wearing a standard helmet (that is, CE (European Standards) and BSI (British Standards Institute) approved); our patient was under the impression that the helmet afforded him full ocular protection. The distance between the peak and grille on our patient's helmet was 2.75 inches at its widest, and 2.5 inches centrally, at its narrowest. The grille has three levels of adjustment up and down and it was on the middle level when the impact was sustained and at which the above measurements were taken. However, the diameter of a cricket ball is just under 2.5 inches at its widest. This allows the ball to clear the grille and reach the eye, especially in a rising trajectory obliquely from the side, $^{8}$ as must have happened in this case. Hence the dent on the side of the helmet as well as the laceration along the lateral orbital margin, in addition to the intraocular damage.

\section{CONCLUSIONS}

It is imperative that a better design and helmet material be introduced so as to prevent and limit such injury. The severity of injury sustained by our patient underscores the importance of rules for eye protection at all levels of play, be they professional, club, or recreational.

\section{Authors' affiliations}

A Abedin, Queen's Medical Centre, Nottingham, UK H-C Chen, Derbyshire Royal Infirmary, Derby, UK

Competing interests: none declared

The patient described in this case report has given consent for his details to be published.

Correspondence to: Asiya Abedin, Queen's Medical Centre, Division of Ophthalmology and Visual Sciences, 8 Floor EENT Building, QMC, Nottingham NG7 2UH, UK; abedin_asiya@hotmail.com

Accepted 23 November 2004

\section{REFERENCES}

1 Barrell GV, Cooper PJ, Elkington AR, et al. Squash ball to eyeball: the likelihood of squash players incurring an eye injury. Br Med J Clin Res Ed $1981 ; 283(6296): 893-5$

2 Aburn N. Eye injuries in indoor cricket at Wellington Hospital: a survey January 1987 to June 1989. N Z Med J 1990;103(898):454-6.

3 Pardhan S, Shacklock P. Weatherall J. Sport-related eye trauma: a survey of the presentation of eye injuries to a casualty clinic and the use of protective eye wear. Eye 1995;9(Pt 6 Su):50-3.

4 Fineman MS, Fischer DH, Jeffer JB, et al. Changing trends in paintball sportrelated ocular injuries. Arch Ophthalmol 2000;118(1):60-4

5 Napier SM, Baker RS, Sanford DG, et al. Eye injuries in athletics and recreation. Surv Ophthalmol 1996;4(3):229-44.

6 Pashby T. Eye injuries in sports. J Ophthalmic Nurs Technol 1989;8(3):99-101.

7 Holmes C. Mouth protection in sport in Scotland - a review. Br Dent J 2000; 188(9):473-4.

8 Jones NP, Tullo AB. Severe eye injuries in cricket. Br J Sports Med 1986;20(4):178-9.

9 Stretch RA. The impact absorption characteristics of cricket batting helmets. J Sports Sci 2000;18(12):959-64.

\section{COMMENTARY}

This case shows the catastrophic and irreversible nature of missile related eye injury to a cricket batsman. It is ironic that he may have believed that his eyes were adequately protected. Pashby has clearly demonstrated that severe eye injury in ice hockey is preventable with adequate eye protection. This author's call for improvements to the eye protection capabilities of cricket helmets must be heeded. However, the implementation of better eye protection may meet resistance within the cricket community. Any perceived minor impairment to vision (that is, by adding a plexiglass shield) will spark a debate as has occurred in ice hockey. Yet even one blinded eye is too many.

\section{J D Carson}

Sunnybrook and Women's College, Health Sciences Center, SportMed North, 255 Main Street, Unionville, Ontario, Canada L3R 2H3; 